\title{
Influence of Vanadium-organic Ligands Treatment on Selected Metal Levels in Kidneys of STZ Rats
}

\author{
Mirosław Krośniak • Joanna Kowalska • \\ Renata Francik • Ryszard Gryboś • Magdalena Blusz • \\ Wojciech M. Kwiatek
}

Received: 24 January 2013 / Accepted: 25 April 2013 / Published online: 11 May 2013

(C) The Author(s) 2013. This article is published with open access at Springerlink.com

\begin{abstract}
The objective of the study was to investigate the effects of five organic vanadium complexes supplement and a small dose of insulin injection on $\mathrm{V}, \mathrm{Fe}, \mathrm{Cu}, \mathrm{Zn}, \mathrm{Mn}, \mathrm{Ca}$, and $\mathrm{K}$ level in the streptozotocin diabetic rat's kidney during a 5-week treatment with the tested complexes. In all groups of animals, metal level in the lyophilized kidney organs was investigated by means of the proton induced X-ray emission method. Tissue vanadium level was naturally higher in vanadium-treated rats. The maximum level of vanadium was observed in the kidney $\left(x_{\text {mean }}=16.6 \mu \mathrm{g} / \mathrm{g}\right)$. The influence of vanadium administration on other metal level in rat's tissue was also investigated. Spectacular influence of vanadium action was observed on copper and zinc level in examined tissue.
\end{abstract}

Keywords STZ rats $\cdot$ Proton-induced X-ray emission · Diabetes · Vanadium $\cdot$ Iron $\cdot$ Copper $\cdot$ Zinc $\cdot$ Manganese $\cdot$ Calcium $\cdot$ Potassium $\cdot$ Kidney

\footnotetext{
M. Krośniak $(\bowtie) \cdot$ M. Blusz

Department of Food Chemistry and Nutrition, Jagiellonian

University Medical College, 30-688 Kraków, Poland

e-mail: mfkrosni@cyf-kr.edu.pl

J. Kowalska • W. M. Kwiatek

Department of Experimental Physics of Complex Systems,

Institute of Nuclear Physics PAN, 31-342 Kraków, Poland

R. Francik

Department of Bioorganic Chemistry, Jagiellonian University

Medical College, 30-688 Kraków, Poland

R. Gryboś

Faculty of Chemistry, Jagiellonian University,

30-060 Kraków, Poland
}

\section{Introduction}

Diabetes is one of the most frequent diseases in developed countries. Every year, the incidence of this disease significantly increases. The prediction for 2030 is more than 500 million persons with diabetes, especially type 2 , worldwide [1]. This phenomenon results primarily from the lifestyle changes: decrease of physical effort and, above all, excess of calories from badly balanced diet, especially from fast food [2-6]. In type 1 diabetes, auto-aggression destroys $\beta$-cells and leads to insulin production atrophy. The mechanism of this type of disease is observed in a lot of laboratories [7, 8]. Insulin production in the pancreas is a multistage process sensitive to glucose level. Also, proper level of microelements, especially zinc $[9,10]$ plays an important role in secretion of this hormone. Type 1 diabetes in an animal model can be provoked by a streptozotocin (STZ) injection which destroys $\beta$-cells within 2-3 days [11-13]. During this time, the glucose level can increase to more than $30 \mathrm{mmol} / \mathrm{l}$, with all symptoms of not treated type 1 diabetes. Since the 1980 s, vanadium compounds have been tested as potential therapeutic agents in type 1 [14-16] and type 2 [17-20] diabetes. Some organic and inorganic vanadium compounds have presented interesting influence on biochemical markers like decrease of glucose level and improvement of other biochemical parameters. Negative effects of vanadium treatment on intestinal tract, such as diarrhea, vomiting etc., have been frequently reported [21, 22]. This was associated with high doses of administered vanadium compounds. Nowadays, scientific attempts concentrate on the decrease of negative effects and increase of therapeutic activity in both diabetes models. In particular, vanadium complexes with organic ligands present interesting proprieties [23-27] and usually higher bioavailability [28]. Some 
Fig. 1 Vanadium level in rat's kidney in different groups of animals ( $D$ diabetic, $D i$ diabetic with insulin, $D i 1$ diabetic with insulin and vanadium complex 1, Di2 diabetic with insulin and vanadium complex $2, \mathrm{Di} 3$ diabetic with insulin and vanadium complex 3, Di4 diabetic with insulin and vanadium complex 4, Di5 diabetic with insulin and vanadium complex $5, C$ control)

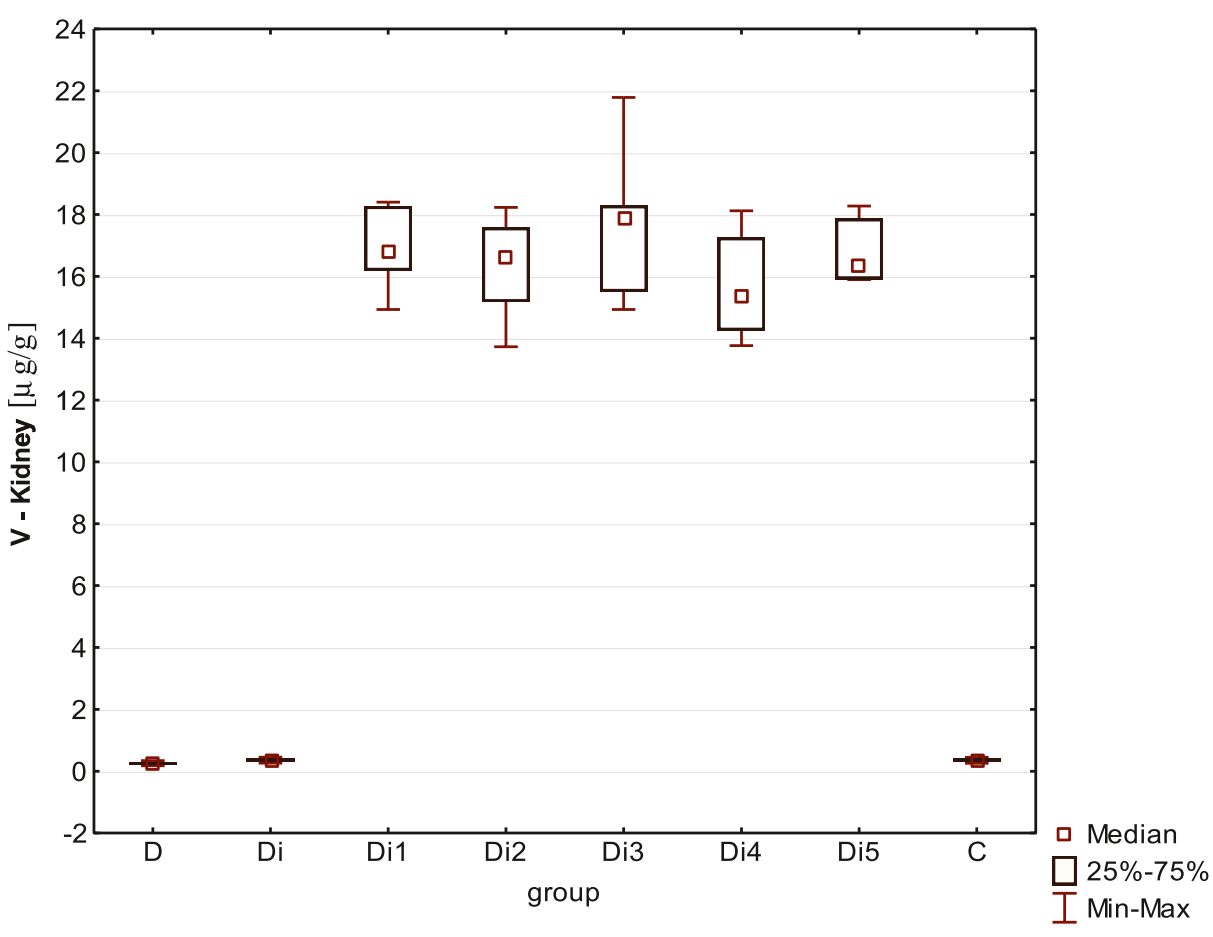

of them have already been tested on patients in clinical trials [26, 27]. Trace elements supplementation in case of vanadium can influence not only biochemical parameters but also other element level in organs [29, 30]. This work focuses on a recondite effect of vanadium treatment on other levels of elements in the kidney of diabetic STZ rats.

\section{Material and Methods}

Animals and Vanadium Administration

Male Wistar rats weighing between 220 and $250 \mathrm{~g}$ were divided into seven groups of six animals in each group. During all time, animals had free access to water and feed. After 3 days from the beginning of the experiment, $55 \mathrm{mg}$ of streptozotocine in citric buffer $(0.1 \mathrm{~mol} / \mathrm{l})$ solution per $1 \mathrm{~kg}$ of body mass was injected into the caudal in all groups of animals. Three days subsequent to the injections, the level of glucose was measured and the glucose level measured in animal blood was higher than $17 \mathrm{mmol} / \mathrm{l}$. After the measurement, the rats were separated into the following tested groups: diabetic control rats (D), diabetic rats with insulin (Di), five groups of diabetic rats with insulin and tested complexes (Di1-5). The tested complexes of vanadium were administered daily in dose of $50 \mu \mathrm{mol} / \mathrm{kg}$ and $1 \mathrm{U} / \mathrm{kg}$ of insulin was injected subcutaneously. Five weeks after beginning of first insulin injection and vanadium complexes administration, animal were anesthetized (thiopental, $50 \mathrm{mg} / \mathrm{kg}$ ) and then the kidneys were collected. For kidney collection, stainless steel chirurgical scissors and tweezers in all groups of animals were used. Kidneys were directly inserted to plastic tubes and kept frozen in $-20{ }^{\circ} \mathrm{C}$ until the time of analysis. Experiment got the agreement from Local Ethic Commission in Krakow ZI/UJ/185/2003.

Table 1 Differences statistically significant for vanadium level between animal groups: $D$ diabetic, $D i$ diabetic with insulin, $D i 1$ diabetic with insulin and vanadium complex $1, D i 2$ diabetic with insulin and vanadium complex 2, Di3 diabetic with insulin and vanadium complex 3, Di4 diabetic with insulin and vanadium complex 4, Di5 diabetic with insulin and vanadium complex $5, C$ control $(* * * p<0.001)$

\begin{tabular}{lllllllll}
\hline & D & Di & Di1 & Di2 & Di3 & Di4 & Di5 & C \\
\hline D & - & & & & & & \\
Di & & - & & & & & \\
Di1 & $* * *$ & $* * *$ & - & & & & \\
Di2 & $* * *$ & $* * *$ & & - & & & \\
Di3 & $* * *$ & $* * *$ & & & - & & \\
Di4 & $* * *$ & $* * *$ & & & & - & \\
Di5 & $* * *$ & $* * *$ & & & & & - & \\
C & & & $* * *$ & $* * *$ & $* * *$ & $* * *$ & $* * *$ & - \\
\hline
\end{tabular}


Fig. 2 Iron level in rat's kidney in different groups of animals ( $D$ diabetic, $D i$ diabetic with insulin, Dil diabetic with insulin and vanadium complex 1, Di2 diabetic with insulin and vanadium complex 2, Di3 diabetic with insulin and vanadium complex 3, Di4 diabetic with insulin and vanadium complex 4, Di5 diabetic with insulin and vanadium complex $5, C$ control)

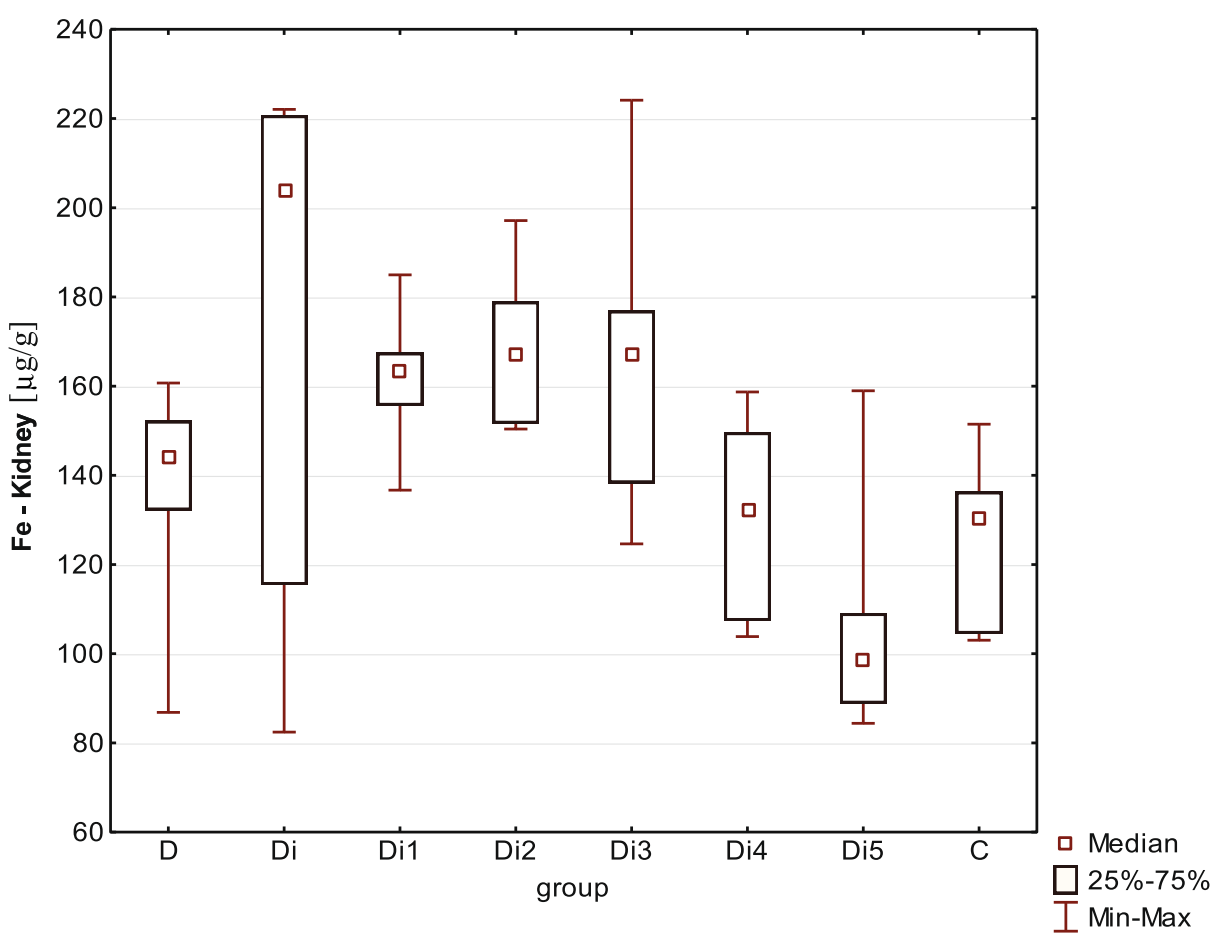

\section{Used complexes}

1. $\mathrm{Na}\left[\mathrm{VO}\left(\mathrm{O}_{2}\right)_{2}\left(2,2^{\prime}\right.\right.$-bpy $\left.)\right] \cdot 8 \mathrm{H}_{2} \mathrm{O}$ (molar mass $=$ $453.94 \mathrm{~g} / \mathrm{mol})$

2. $\mathrm{Na}\left[\mathrm{VO}\left(\mathrm{O}_{2}\right)_{2}\left(1,10^{\prime}\right.\right.$-phen) $] \cdot 5 \mathrm{H}_{2} \mathrm{O}$ (molar mass $=$ $423.94 \mathrm{~g} / \mathrm{mol})$

3. $\mathrm{Na}\left[\mathrm{VO}\left(\mathrm{O}_{2}\right)_{2}\left(4,4^{\prime}-\mathrm{Me}-2,2^{\prime}-\right.\right.$ bpy $\left.)\right] \cdot 8 \mathrm{H}_{2} \mathrm{O}$ (molar mass $=$ $481.94 \mathrm{~g} / \mathrm{mol})$

4. $\left[\mathrm{VO}\left(\mathrm{SO}_{4}\right)\left(1,10^{\prime}\right.\right.$-phen $\left.)\right] \cdot 2 \mathrm{H}_{2} \mathrm{O}$ (molar mass $=$ $363 \mathrm{~g} / \mathrm{mol})$

5. $\left[\mathrm{VO}\left(\mathrm{SO}_{4}\right)\left(2,2^{\prime}-\mathrm{bpy}\right)\right] \cdot \mathrm{H}_{2} \mathrm{O}($ molar mass $=321 \mathrm{~g} / \mathrm{mol})$

where synthesized by the method described in the literature [31-33].

Used abbreviation: bpy, bypiridyne; phen, phenanthroline, and Me, methyl. Their purity was confirmed by elemental analysis and infrared spectroscopy.

\section{Kidney Tissue Preparation}

Frozen kidney tissue was transferred directly to lyophilizing cabinet and lyophilized using ABCONO FREEZONE 4,5 in temperature from -40 to $-53{ }^{\circ} \mathrm{C}$, and under pressure of 14-1 $\mathrm{Pa}$. Then, the lyophilized kidney tissue was homogenated in agate mortar and pressed into pellets, about $1 \mathrm{~mm}$ thick and $10 \mathrm{~mm}$ in diameter, by pressure of $15 \mathrm{MPa}$ in home-made apparatus. Such pellets were placed on Scotch tape and attached to an aluminum frame.
Proton-induced X-ray Emission Analysis

A $2 \mathrm{MeV}$ proton beam from the Van de Graaff accelerator was directed at the sample for a multitrace $(\mathrm{K}, \mathrm{Ca}, \mathrm{Mn}, \mathrm{Fe}$, $\mathrm{Cu}, \mathrm{Zn}$, and V) element analysis. Each sample was measured twice. Standard Reference Material 1577b Bovine Liver was also used. All the collected spectra were analyzed using GupixWin ver. 2.0 software. The statistical calculations were performed using Statistica 7.1 program. Differences between the studied rat groups were estimated using a

Table 2 Differences statistically significant for iron level between animal groups: $D$ diabetic, $D i$ diabetic with insulin, $D i 1$ diabetic with insulin and vanadium complex $1, D i 2$ diabetic with insulin and vanadium complex 2, Di3 diabetic with insulin and vanadium complex 3, Di4 diabetic with insulin and vanadium complex 4, Di5 diabetic with insulin and vanadium complex $5, C$ control $\left({ }^{*} p<0.05\right)$

\begin{tabular}{|c|c|c|c|c|c|c|c|c|}
\hline & $\mathrm{D}$ & Di & Di1 & Di2 & Di3 & Di4 & Di5 & $\mathrm{C}$ \\
\hline $\mathrm{D}$ & - & & & & & & & \\
\hline Di & & - & & & & & & \\
\hline Di1 & & & - & & & & & \\
\hline Di2 & & & & - & & & & \\
\hline Di3 & & & & & - & & & \\
\hline Di4 & & & & & & - & & \\
\hline Di5 & & & $*$ & & & & - & \\
\hline $\mathrm{C}$ & & & & & & & & - \\
\hline
\end{tabular}


Fig. 3 Copper level in rat's kidney in different groups of animals ( $D$ diabetic, $D i$ diabetic with insulin, Dil diabetic with insulin and vanadium complex 1, Di2 diabetic with insulin and vanadium complex 2, Di3 diabetic with insulin and vanadium complex 3, Di4 diabetic with insulin and vanadium complex 4, Di5 diabetic with insulin and vanadium complex $5, C$ control)

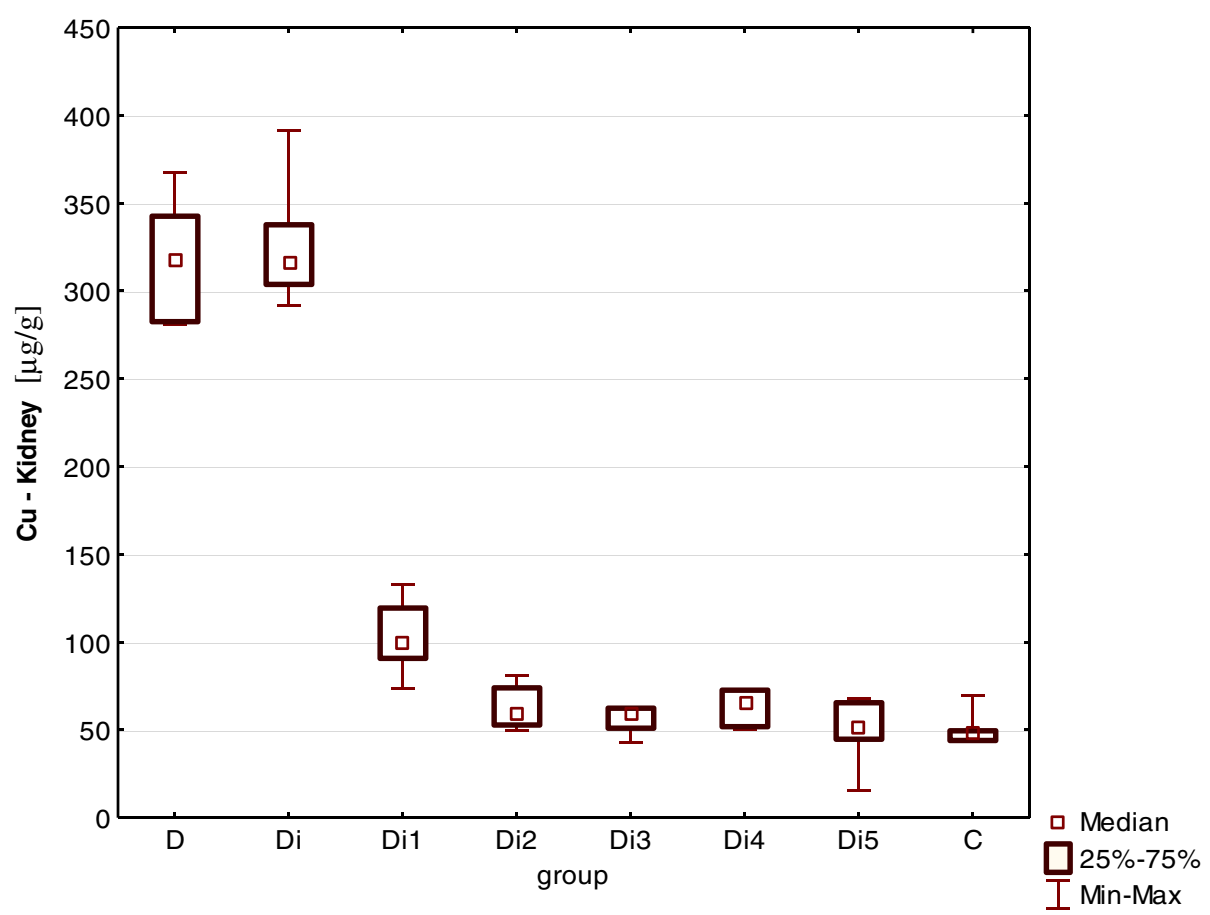

nonparametric Kruskal-Wallis test. Full methodology was described in Acta Pol Pharm (2013) 70: 71-77.

\section{Results}

Vanadium In all vanadium-treated animal groups, the level of this element was significantly $(p<0.001)$ higher in comparison to not treated groups (Fig. 1 and Table 1). No differences were observed between the vanadium organoligands used. Similar absence of differences was observed in animal groups not treated with vanadium.

Iron Iron level in the kidney presented only one significant difference between the two tested vanadium organoligands-Dil vs. Di5 (Fig. 2 and Table 2). The obtained results indicate higher level of this metal in diabetic animals as compared to the control group. Presumably, more numerous groups would have shown significant differences.

Copper The copper level in the kidney is evidently associated with diabetes. In diabetic animals not treated with vanadium, the copper level was significantly higher in comparison to vanadium-treated rats and control groups. Vanadium treatment has reduced the level of this metal to a value close to the control group (Fig. 3 and Table 3). Vanadium compound used in the
Dil group had a lesser influence on copper decrease in diabetic animals.

Zinc Vanadium treatment had very high influence on zinc level in the kidney (Fig. 4 and Table 4). The obtained results have shown the decrease of zinc level in all vanadiumtreated groups $(p<0.01)$. On the other hand, diabetes increases the level of zinc in the kidney in comparison to the control group.

Table 3 Differences statistically significant for copper level between animal groups: $D$ diabetic, $D i$ diabetic with insulin, $D i 1$ diabetic with insulin and vanadium complex $1, D i 2$ diabetic with insulin and vanadium complex 2, Di3 diabetic with insulin and vanadium complex 3, Di4 diabetic with insulin and vanadium complex 4, Di5 diabetic with insulin and vanadium complex $5, C$ control $\left({ }^{*} p<0.05,{ }^{* *} p<0.01, * * * p\right.$ $<0.001)$

\begin{tabular}{lllllllll}
\hline & D & Di & Di1 & Di2 & Di3 & Di4 & Di5 & C \\
\hline D & - & & & & & & \\
Di & & - & & & & & \\
Di1 & $*$ & $*$ & - & & & & \\
Di2 & $* *$ & $* *$ & & - & & & \\
Di3 & $* *$ & $* *$ & & & - & & \\
Di4 & $* *$ & $* *$ & & & & - & \\
Di5 & $* *$ & $* *$ & & & & & - \\
C & $* * *$ & $* * *$ & $*$ & & & & & \\
\hline
\end{tabular}


Fig. 4 Zinc level in rat's kidney in different groups of animals ( $D$ diabetic, $D i$ diabetic with insulin, Dil diabetic with insulin and vanadium complex $1, D i 2$ diabetic with insulin and vanadium complex 2, Di3 diabetic with insulin and vanadium complex 3, Di4 diabetic with insulin and vanadium complex $4, D i 5$ diabetic with insulin and vanadium complex $5, C$ control)

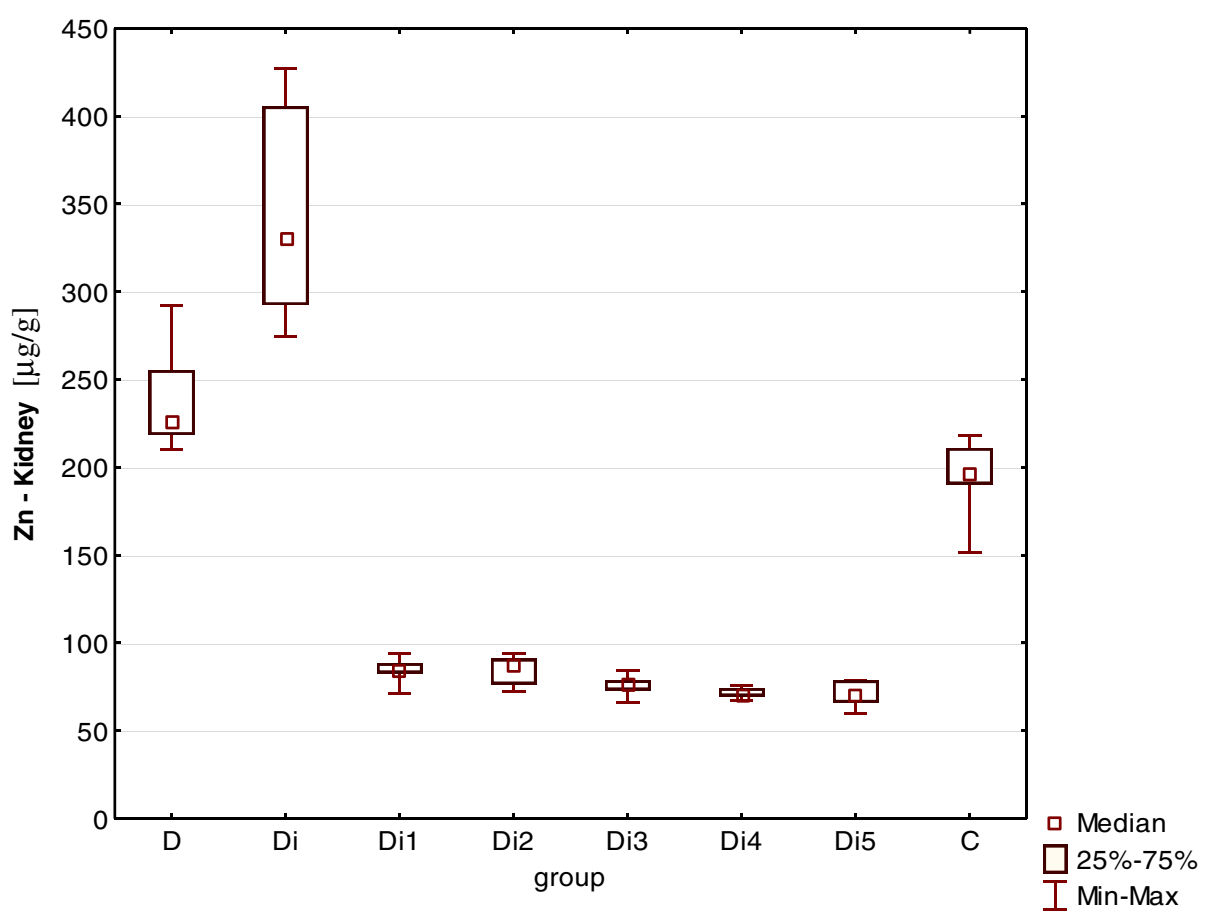

Manganese The manganese level in the kidney is associated with vanadium treatment. In all groups with vanadium administration, the level of manganese was higher in comparison to diabetic one and to control group (Fig. 5 and Table 5). No differences were observed between the vanadium organoligands used.

Calcium The calcium level in the kidney seems to be not associated with vanadium treatment. The increase of the calcium level in the kidney in the diabetic animals

Table 4 Differences statistically significant for zinc level between animal groups: $D$ diabetic, $D i$ diabetic with insulin, $D i 1$ diabetic with insulin and vanadium complex 1, Di2 diabetic with insulin and vanadium complex 2, Di3 diabetic with insulin and vanadium complex 3, Di4 diabetic with insulin and vanadium complex $4, D i 5$ diabetic with insulin and vanadium complex $5, C$ control $\left({ }^{*} p<0.05,{ }^{* *} p<0.01, * * * p<0.001\right)$

\begin{tabular}{lllllllll}
\hline & D & Di & Di1 & Di2 & Di3 & Di4 & Di5 & C \\
\hline D & - & & & & & & \\
Di & & - & & & & & \\
Di1 & $*$ & $* *$ & - & & & & \\
Di2 & $*$ & $* *$ & & - & & & \\
Di3 & $*$ & $* *$ & & & - & & \\
Di4 & $* *$ & $* * *$ & & & & - & & \\
Di5 & $* *$ & $* * *$ & & & & & - & \\
C & & $*$ & $*$ & $*$ & $*$ & $*$ & $*$ & - \\
\hline
\end{tabular}

was statistically significant in comparison to the control group (Fig. 6 and Table 6). However, in all diabetic groups, both with and without vanadium treatment, the calcium level was similar and higher than in case of the control group.

Potassium The potassium level was highest in diabetic and diabetic with insulin groups. Lowest level of potassium was observed in group treated with complex 4 (Fig. 7 and Table 7). The differences were statistically significant. Also, significant differences associated with type of vanadium compound were observed between groups Di1 and Di4.

\section{Discussion}

Diabetes and especially not treated diabetes deteriorating kidney function [34-36]. An increased glucose level in the blood during diabetes negatively influences the efficiency of this organ. An increase of thirst and urine production [37] in not treated diabetes is visible. A high glucose level and hypertension have principal role in diabetic nephropathy. The dysfunction of the kidney drastically changes the total organism homeostasis and can cause death from renal failure. The most important role of the kidney is water and mineral recovery and elimination of nitrogen metabolites. High urine production by diabetic rats can cause loss of vital 
Fig. 5 Manganese level in rat's kidney in different groups of animals ( $D$ diabetic, $D i$ diabetic with insulin, $D i 1$ diabetic with insulin and vanadium complex 1, Di2 diabetic with insulin and vanadium complex $2, \mathrm{Di} 3$ diabetic with insulin and vanadium complex 3, Di4 diabetic with insulin and vanadium complex 4, Di5 diabetic with insulin and vanadium complex $5, C$ control)

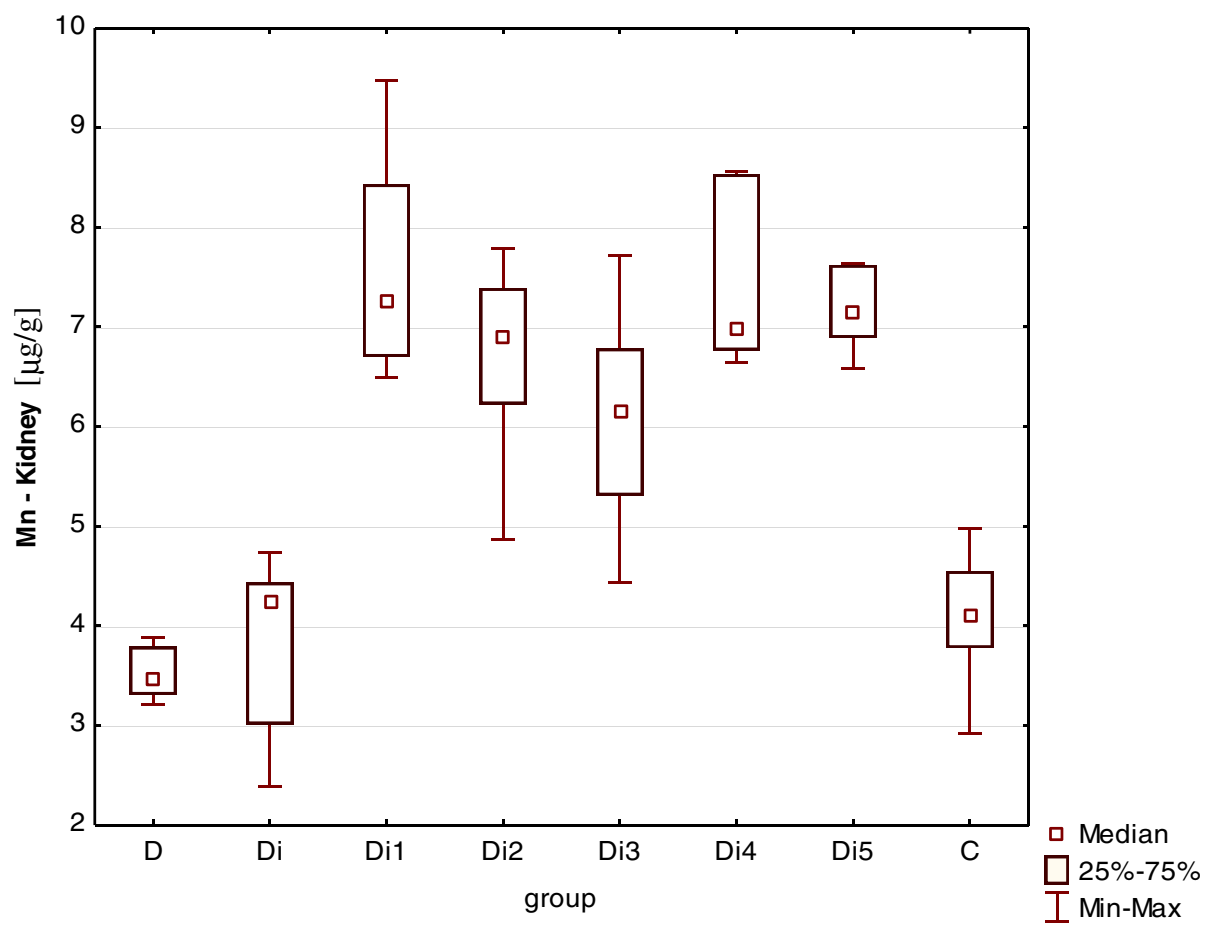

elements, which can increase the organism dysfunction [38]. Vanadium administration in rats evidently increases the level of this element in the kidney more than 10 times in comparison to animals not treated with vanadium. This observation is similar for other studies in which the accumulation of vanadium in organs was observed after the treatment with ions of this metal [39-41]. The vanadium absorption from the gastrointestinal tract is associated with chemical structure of used compound. In case of used complexes in the present experiment, only two complexes ( 1 and

Table 5 Differences statistically significant for manganese level between animal groups: $D$ diabetic, $D i$ diabetic with insulin, $D i 1$ diabetic with insulin and vanadium complex 1, Di2 diabetic with insulin and vanadium complex 2, Di3 diabetic with insulin and vanadium complex 3, Di4 diabetic with insulin and vanadium complex 4, Di5 diabetic with insulin and vanadium complex $5, C$ control $\left({ }^{*} p<0.05,{ }^{*} p<0.01\right)$

\begin{tabular}{lllllllll}
\hline & D & Di & Di1 & Di2 & Di3 & Di4 & Di5 & C \\
\hline D & - & & & & & & \\
Di & & - & & & & & \\
Di1 & $*$ & $*$ & - & & & & \\
Di2 & $*$ & $*$ & & - & & & \\
Di3 & $*$ & $*$ & & & - & & \\
Di4 & $* *$ & $* *$ & & & & - & & \\
Di5 & $* *$ & $* *$ & & & & & - & \\
C & & & $*$ & $*$ & & $*$ & $*$ & - \\
\hline
\end{tabular}

5) had pharmacokinetic study [28]. Bioavailability of these complexes was $27-30 \%$ and was higher in comparison to vanadyl sulfate was $-18 \%$. For other complexes, pharmacokinetics study was not made for this time. An interesting observation was noted for zinc and copper levels. STZinduced diabetes statistically increases both elements levels. Similar effects were reported by Sivikaya et al. [42] for not treated STZ diabetes in the kidney. The increase of both elements can give information about an important role of these metals in diabetes development. It is probably associated with an increased uptake of zinc and copper in the kidney from blood during urine production. Treatment with vanadium in our work and with zinc in Sivikaya et al. work decreased levels of both elements in the kidney tissue. Vanadium complexes administered in a dose of $20 \mathrm{mg} / \mathrm{kg} /$ day (about 5-6 mg of pure vanadium depending of compound per kilogram per day) had higher influence on the zinc and copper level in the kidney than zinc in Sivikaya et al. work. As for copper, the level in all vanadium-treated groups was similar to the control group. The diabetic groups which were not treated with vanadium sometimes showed higher levels of copper than the control group. In the work of Sivikaya et al., zinc level in the kidney in zinc-treated animals was higher but zinc treatment can influence the total zinc level in the kidney. The question is if this increase of zinc and copper in the kidney of diabetic, not treated animal is associated with higher diuresis and/or elimination of these elements from other 
Fig. 6 Calcium level in rat's kidney in different groups of animals ( $D$ diabetic, $D i$ diabetic with insulin, Dil diabetic with insulin and vanadium complex 1, Di2 diabetic with insulin and vanadium complex 2, Di3 diabetic with insulin and vanadium complex 3 , Di4 diabetic with insulin and vanadium complex 4 , Di5 diabetic with insulin and vanadium complex 5 , $C$ control)

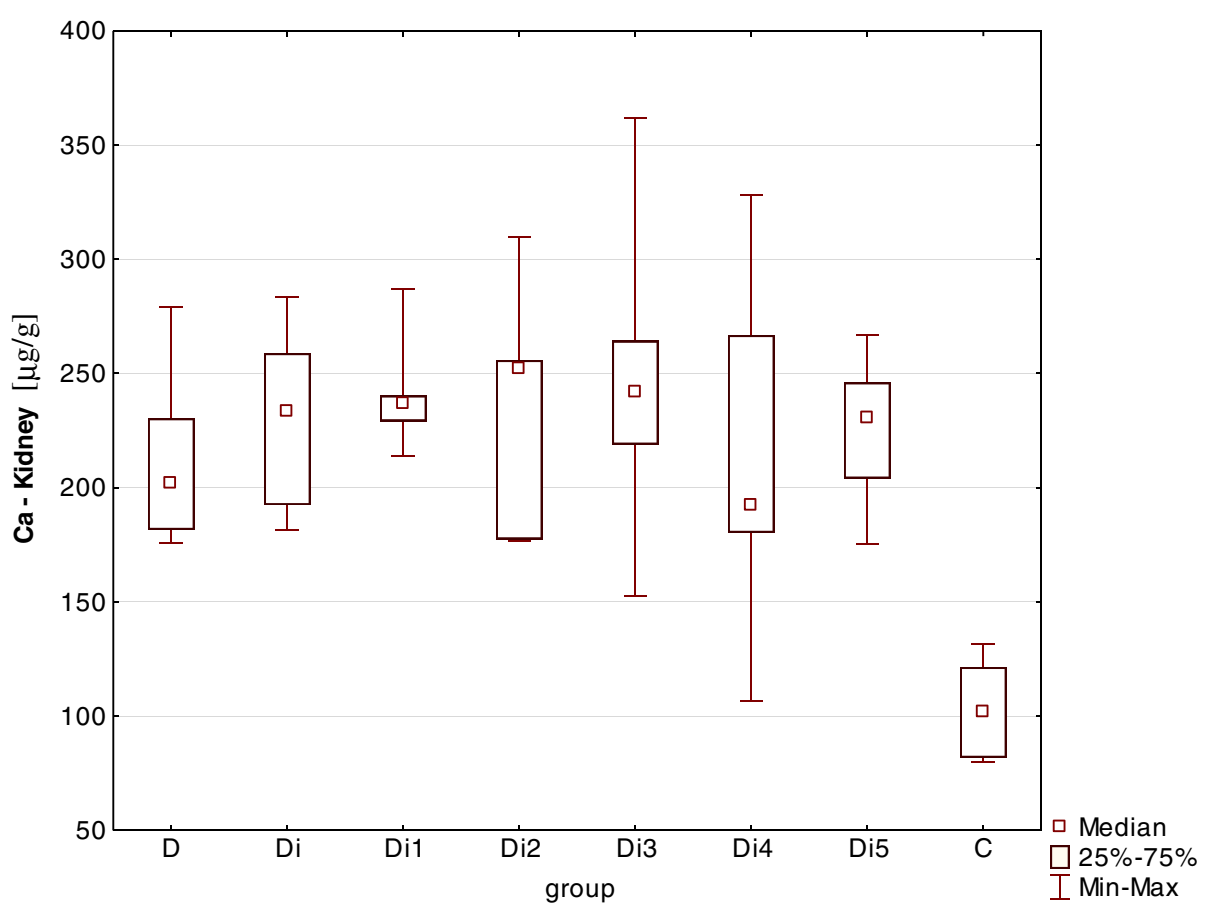

tissues. The increase of zinc and copper in those cases could possibly be explained by the fact that the accumulation of these elements in the kidney occurs to protect the organism from an important element loss. Zinc has an especially important role in insulin production and in protecting the organism against free radicals. There may also be a different explanation of the zinc and copper increase in the vanadium-treated animals. Streptozotocin destroys pancreatic island cells and after STZ administration zinc is eliminated also from the pancreas.

Table 6 Differences statistically significant for calcium level between animal groups: $D$ diabetic, $D i$ diabetic with insulin, $D i 1$ diabetic with insulin and vanadium complex $1, D i 2$ diabetic with insulin and vanadium complex 2, Di3 diabetic with insulin and vanadium complex 3, Di4 diabetic with insulin and vanadium complex 4, Di5 diabetic with insulin and vanadium complex $5, C$ control $\left({ }^{*} p<0.05\right)$

\begin{tabular}{lllllllll}
\hline & D & Di & Di1 & Di2 & Di3 & Di4 & Di5 & C \\
\hline D & - & & & & & & \\
Di & & - & & & & & \\
Di1 & & & - & & & & \\
Di2 & & & & - & & & \\
Di3 & & & & & - & & \\
Di4 & & & & & & - & \\
Di5 & & & & & & & - \\
C & $*$ & $*$ & $*$ & $*$ & $*$ & & $*$ & - \\
\hline
\end{tabular}

As for the calcium level in the kidney, an increase of this element in all diabetic groups was observed. Adding vanadium compounds did not affect the level of calcium in the tested tissue in all groups of animals (both treated and not treated). It is, therefore, possible to form a hypothesis that the calcium level in the kidney is closely connected with diabetes, both treated and not treated with vanadium compounds. The observed results are similar to the ones in the work of Dogru Pekine et al. [43]. A different effect was observed in Sivikaya et al. [42] where zinc treatment in STZ diabetic rats caused a decrease of the calcium level in the kidney of the animals.

The manganese level was statistically higher in all the vanadium-treated groups in comparison to the control and diabetic vanadium not-treated groups. It is difficult to compare the obtained results with other works because so far the vanadium and manganese interaction was not tested in the STZ diabetic model in the kidney. In the work of Sakai et al. [44], an interaction between zinc and manganese in diabetic animals showed a similar increase of manganese in the kidney in zinc-treated animals.

The iron level in the kidney was the most variable element. Diabetes presented a trend in its increase in comparison to the control group but it was not significant. Vanadium treatment, especially the type of used complex, resulted in differences between all the five tested vanadium organoligands. Three of the tested complexes-1, 2, and 3 - statistically increase the iron level in the kidney in comparison to the control group. On the other hand, the 
Fig. 7 Potassium level in rat's kidney in different groups of animals ( $D$ diabetic, $D i$ diabetic with insulin, Dil diabetic with insulin and vanadium complex $1, D i 2$ diabetic with insulin and vanadium complex $2, \mathrm{Di} 3$ diabetic with insulin and vanadium complex 3, Di4 diabetic with insulin and vanadium complex 4, Di5 diabetic with insulin and vanadium complex $5, C$ control)

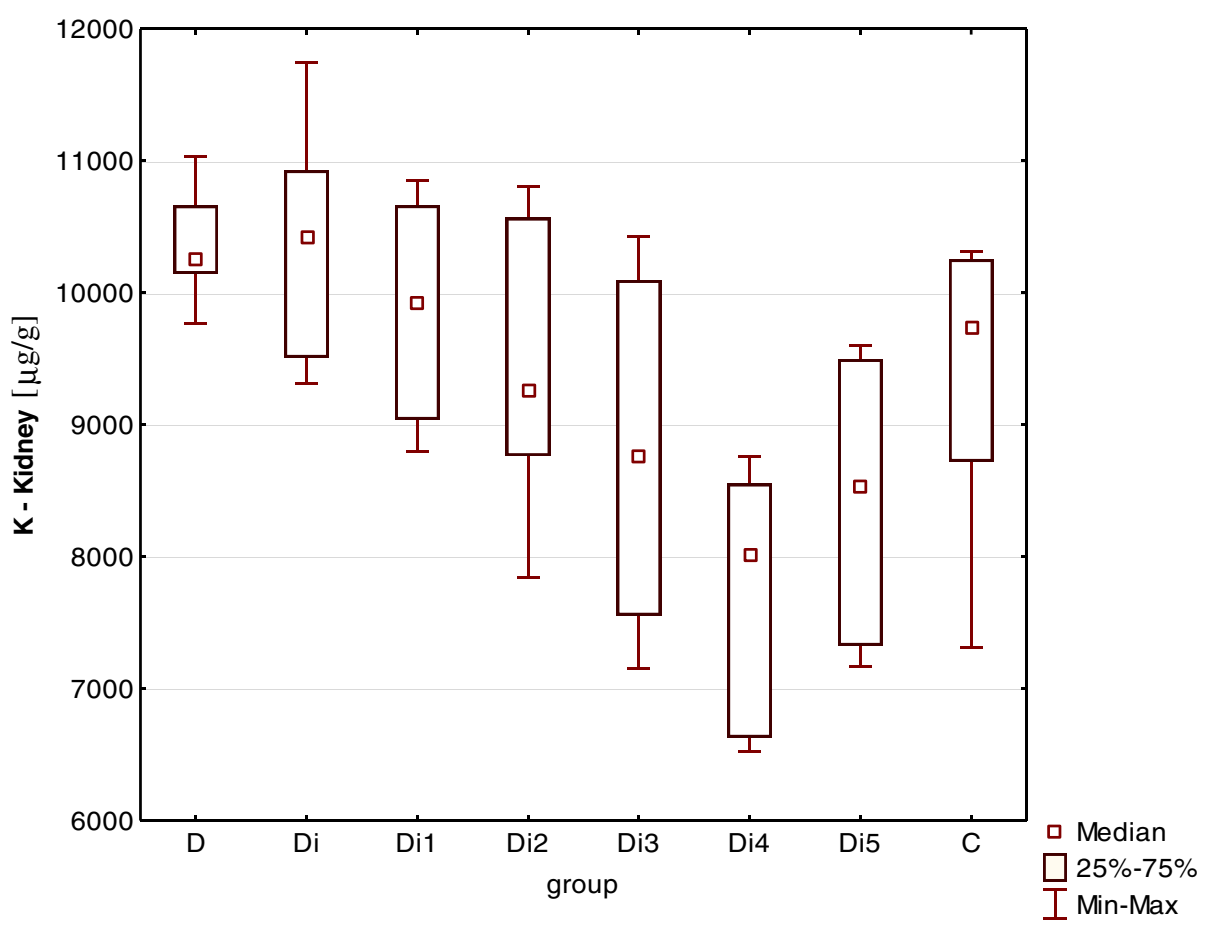

complex of vanadium five (Di5) decreased the iron level in the kidney in diabetic vanadium-treated animals in comparison to the control group. Differences between vanadium compounds and their influence on the iron level in the kidney were observed by Thompson et al. [45], but they preformed an experiment with healthy animals. These differences may be associated with an oxidation state or absorption from the intestinal system.

All vanadium complexes used in the experiment were with organoligands. The changes observed in the level of the

Table 7 Differences statistically significant for potassium level between animal groups: $D$ diabetic, $D i$ diabetic with insulin, $D i 1$ diabetic with insulin and vanadium complex 1, Di2 diabetic with insulin and vanadium complex 2, Di3 diabetic with insulin and vanadium complex 3, Di4 diabetic with insulin and vanadium complex 4, Di5 diabetic with insulin and vanadium complex $5, C$ control $\left({ }^{*} p<0.05\right)$

\begin{tabular}{lllllllll}
\hline & D & Di & Di1 & Di2 & Di3 & Di4 & Di5 & C \\
\hline D & - & & & & & & \\
Di & & & & & & & \\
Di1 & & & & & & & \\
Di2 & & & & & & & \\
Di3 & & & & & & & \\
Di4 & $*$ & $*$ & $*$ & & & & \\
Di5 & & & & & & & \\
C & & & & & & & \\
\hline
\end{tabular}

other elements were similar for the tested complexes in all cases except for the iron level. It can suggest that the type of organic ligand used has minimal influence on the measured metal level and the observed results are associated only with the vanadium action and its oxidation state. Probably, bioavailabilities of all tested complexes are very similar and animals had the some vanadium intake by examined organ. In case of iron, the situation is more complicated. Evidently, influence of used organoligands can be observed. It is especially exposed for complexes 1, 2, and 3 versus complex 5 . This can suggests that the iron level can be correlated with an oxidation state of vanadium. In complexes $1-3$, it is the vanadium (IV) oxidation state and for 4 and 5 , it is vanadium (V) oxidation state. Analyzed interaction between iron level in kidney and vanadium treatment are few and require further research to verify the presented hypothesis. The obtained results also suggest that there are changes in metal levels in the investigated organ (the kidney) associated with diabetes. Metal supplementation can probably be useful in the treatment of this disease but further studies are required to confirm these findings. Another problem is contamination of used stainless steel chirurgical scissors and tweezers for iron and manganese level in kidney. During organ collection, the same procedure was used. Probability of contamination of the samples of these metals is very similar. Large differences of metals level in the analyzed samples was not observed within the groups and this suggesting about of comparable cross-contamination within the treatment group. 
Acknowledgments We would like to express our gratitude to Prof. Janine Brès for her advice and to Krzysztof Ryt for the samples of liophilization. This work has been partially supported by an individual grant $\mathrm{WL} / 403 / \mathrm{P} / \mathrm{F}$

Open Access This article is distributed under the terms of the Creative Commons Attribution License which permits any use, distribution, and reproduction in any medium, provided the original author(s) and the source are credited.

\section{References}

1. http://www.idf.org/media-events/press-releases/2011/diabetes-atlas5th-edition. Accessed 14 August 2012

2. http://ki.se/content/1/c6/04/90/19/AnimeshBiswas.pdf. Accessed 14 August 2012

3. http://www.nice.org.uk/nicemedia/live/13472/54345/54345.pdf. Accessed 14 August 2012

4. http://diabetes.niddk.nih.gov/dm/pubs/amIatrisktype2AI/ amerindrisk.pdf. Accessed 14 Aug 2012

5. Mohan V, Sandeep S, Deepa R, Shah B, Varghese C (2007) Epidemiology of type 2 diabetes: Indian scenario. Indian J Med Res 125:217-230

6. Odegaard AO, Koh WP, Yuan JM, Gross MD, Pereira MA (2012) Western-style fast food intake and cardiometabolic risk in an eastern country. Circulation 126:182-188

7. Hänninen A, Nurmela R, Maksimow M, Heino J, Jalkanen S, Kurts C (2007) Islet beta-cell-specific T cells can use different homing mechanisms to infiltrate and destroy pancreatic islets. Am J Pathol 170:240-250, Erratum in: Am J Pathol. 2008; $172: 1153$

8. Von Herrath M, Rottembourg D, Bresson D (2006) Progress in the development of immune-based therapies for type 1 diabetes mellitus. BioDrugs 20:341-350

9. Bosco MD, Mohanasundaram DM, Drogemuller CJ, Lang CJ, Zalewski PD, Coates PT (2010) Zinc and zinc transporter regulation in pancreatic islets and the potential role of zinc in islet transplantation. Rev Diabet Stud 7:263-274. doi:10.1900/ RDS.2010.7.263

10. Bideci A, Camurdan MO, Cinaz P, Dursun H, Demirel F (2005) Serum zinc, insulin-like growth factor-I and insulin-like growth factor binding protein-3 levels in children with type 1 diabetes mellitus. J Pediatr Endocrinol Metab 18:1007-1011

11. Yoon JW, Kim CJ, Pak CY, McArthur RG (1987) Effects of environmental factors on the development of insulin-dependent diabetes mellitus. Clin Invest Med 10:457-469

12. Lee SH, Park IS (2000) Effects of soybean diet on the beta cells in the streptozotocin treated rats for induction of diabetes. Diabetes Res Clin Pract 47:1-13

13. Ozawa Y, Kurihara T, Sasaki M, Ban N, Yuki K, Kubota S, Tsubota K (2011) Neural degeneration in the retina of the streptozotocin-induced type 1 diabetes model. Exp Diabetes Res 2011:108328. doi:10.1155/2011/108328

14. Heyliger CE, Tahiliani AG, McNeill JH (1985) Effect of vanadate on elevated blood glucose and depressed cardiac performance of diabetic rats. Science 227:1474-1477

15. Iglesias-González T, Sánchez-González C, Montes-Bayón M, Llopis-González J, Sanz-Medel A (2012) Absorption, transport and insulin-mimetic properties of bis(maltolato)oxovanadium (IV) in streptozotocin-induced hyperglycemic rats by integrated mass spectrometric techniques. Anal Bioanal Chem 402:277-285
16. Ahmadi S, Karimian SM, Sotoudeh M, Bahadori M, Dehghani GA (2010) Pancreatic islet beta cell protective effect of oral vanadyl sulphate in streptozotocin-induced diabetic rats, an ultrastructure study. Pak J Biol Sci 13:1135-1140

17. Thompson KH, Lichter J, LeBel C, Scaife MC, McNeill JH, Orvig C (2009) Vanadium treatment of type 2 diabetes: a view to the future. J Inorg Biochem 103:554-558

18. Smith DM, Pickering RM, Lewith GT (2008) A systematic review of vanadium oral supplements for glycaemic control in type 2 diabetes mellitus. QJM 101:351-358

19. Karmaker S, Saha TK, Yoshikawa Y, Sakurai H (2007) Amelioration of hyperglycemia and metabolic syndromes in type 2 diabetic KKA(y) mice by poly(gamma-glutamic acid)oxovanadium(IV) complex. ChemMedChem 2:1607-1612

20. Adachi Y, Yoshikawa Y, Yoshida J, Kodera Y, Katoh A, Takada J, Sakurai H (2006) Improvement of diabetes, obesity and hypertension in type 2 diabetic KKAy mice by bis(allixinato)oxovanadium(IV) complex. Biochem Biophys Res Commun 345:945-950

21. Llobet JM, Domingo JL (1984) Acute toxicity of vanadium compounds in rats and mice. Toxicol Lett 23:227-231

22. Boulassel B, Sadeg N, Roussel O, Perrin M, Belhadj-Tahar H (2011) Fatal poisoning by vanadium. Forensic Sci Int 206:e79-e81

23. Li M, Smee JJ, Ding W, Crans DC (2009) Anti-diabetic effects of sodium 4-amino-2,6-dipicolinatodioxovanadium(V) dihydrate in streptozotocin-induced diabetic rats. J Inorg Biochem 103:585-589

24. Reul BA, Amin SS, Buchet JP, Ongemba LN, Crans DC, Brichard SM (1999) Effects of vanadium complexes with organic ligands on glucose metabolism: a comparison study in diabetic rats. $\mathrm{Br} \mathrm{J}$ Pharmacol 126:467-477

25. Wei Y, Zhang C, Zhao P, Yang X, Wang K (2011) A new salicylic acid-derivatized kojic acid vanadyl complex: synthesis, characterization and anti-diabetic therapeutic potential. J Inorg Biochem 105:1081-1085

26. Thompson KH, Orvig C (2006) Vanadium in diabetes: 100 years from phase 0 to phase I. J Inorg Biochem 100:1925-1935

27. Goldfine AB, Patti ME, Zuberi L, Goldstein BJ, LeBlanc R, Landaker EJ, Jiang ZY, Willsky GR, Kahn CR (2000) Metabolic effects of vanadyl sulfate in humans with non-insulin-dependent diabetes mellitus: in vivo and in vitro studies. Metabolism 49:400-410

28. Krosniak M, Azay-Milhau J, Gryboś R, , Cros G, Gatacceca F, Brés J (2008) Vanadium pharmacokinetics and bioavailability of two vanadium bipyridine complexes, with reference to vanadyl sulfate, after oral administration to streptozotocin-induced diabetic rats. Metal ions in biology and medicine Vol. 10. Libbey: Paris, 769-775

29. Sánchez C, Torres M, Bermúdez-Peña MC, Aranda P, MontesBayón M, Sanz-Medel A, Llopis J (2011) Bioavailability, tissue distribution and hypoglycaemic effect of vanadium in magnesiumdeficient rats. Magnes Res 24:196-208

30. Edel AL, Kopilas M, Clark TA, Aguilar F, Ganguly PK, Heyliger CE, Pierce GN (2006) Short-term bioaccumulation of vanadium when ingested with a tea decoction in streptozotocin-induced diabetic rats. Metabolism 55:263-270

31. Krośniak M, Zachwieja Z, Filipek B, Zygmunt M, Gryboś R (2001) Effect of oxovanadium(IV) complexes on nondiabetic and streptozotocin-diabetic rats. Arch Pharm Pharm Med Chem 334:373-374

32. Przybylski W, Gryboś R, Rehder D, Ebel M, Grzywa M, Łasocha W, Lewiński K, Szklarzewicz JT (2009) Role of the alkali metal ion and hydrogen bonds in $\mathrm{M}\left[\mathrm{VO}\left(\mathrm{O}_{2}\right)_{2}\right.$ bpy] $\mathrm{nH}_{2} \mathrm{O}\left(\mathrm{M}=\mathrm{Li}^{+}, \mathrm{Na}^{+}, \mathrm{K}^{+}\right.$and $\left.\mathrm{Rb}^{+}\right)$and $\mathrm{Cs}\left[\mathrm{VO}\left(\mathrm{O}_{2}\right)_{2}\right.$ bpy $] \mathrm{H}_{2} \mathrm{O}_{2}$ complexes: the X-ray crystal structures and spectroscopic properties. Polyhedron 28:1429-1436

33. Krośniak M, Gawlik M, Gryboś R (2009) Effect of vanadium complexes and insulin administered simultaneously for oxidative stress in STZ diabetic rats. Bull Vet Inst Pulawy 53:535-540 
34. Karihaloo A (2012) Anti-fibrosis therapy and diabetic nephropathy. Curr Diab Rep 12:414-422

35. Pyram R, Kansara A, Banerji MA, Loney-Hutchinson L (2012) Chronic kidney disease and diabetes. Maturitas 71:94-103

36. Bakris GL (2011) Recognition, pathogenesis, and treatment of different stages of nephropathy in patients with type 2 diabetes mellitus. Mayo Clin Proc 86:444-456

37. Samarasinghe S, Vokes T (2006) Diabetes insipidus. Expert Rev Anticancer Ther Suppl 9:S63-S74

38. Ozcelik D, Tuncdemir M, Ozturk M, Uzun H (2011) Evaluation of trace elements and oxidative stress levels in the liver and kidney of streptozotocin-induced experimental diabetic rat model. Gen Physiol Biophys 30:356-363

39. Zhang SQ, Zhong XY, Chen GH, Lu WL, Zhang Q (2008) The anti-diabetic effects and pharmacokinetic profiles of bis(maltolato)oxovanadium in non-diabetic and diabetic rats. J Pharm Pharmacol 60:99-105

40. Zhang SQ, Zhong XY, Lu WL, Zheng L, Zhang X, Sun F, Fu GY, Zhang Q (2005) Pharmacodynamics and pharmacokinetics of the insulin-mimetic agent vanadyl acetylacetonate in non-diabetic and diabetic rats. J Inorg Biochem 99:1064-1075
41. Kowalska J, Krośniak M, Gryboś R, Kwiatek WM (2009) Investigation of trace element concentration in diabetic rat's tissues. Acta Phys Polon A 115:556-560

42. Sivrikaya A, Bicer M, Akil M, Baltaci AK, Mogulkoc R (2012) Effects of zinc supplementation on the element distribution in kidney tissue of diabetic rats subjected to acute swimming. Biol Trace Elem Res 147:195-199

43. Dogru Pekiner B, Daş Evcimen N, Ulusu NN, Bali M, Karasu C (2003) Effects of vitamin $\mathrm{E}$ on microsomal $\mathrm{Ca}(2+)$-ATPase activity and calcium levels in streptozotocin-induced diabetic rat kidney. Cell Biochem Funct 21:177-182

44. Sakai T, Miki F, Wariishi M, Yamamoto S (2004) Comparative study of zinc, copper, manganese, and iron concentrations in organs of zinc-deficient rats and rats treated neonatally with L-monosodium glutamate. Biol Trace Elem Res 97:163-182

45. Thompson KH, Tsukada Y, Xu Z, Battell M, McNeill JH, Orvig C (2002) Influence of chelation and oxidation state on vanadium bioavailability, and their effects on tissue concentrations of zinc, copper, and iron. Biol Trace Elem Res 86:3144 